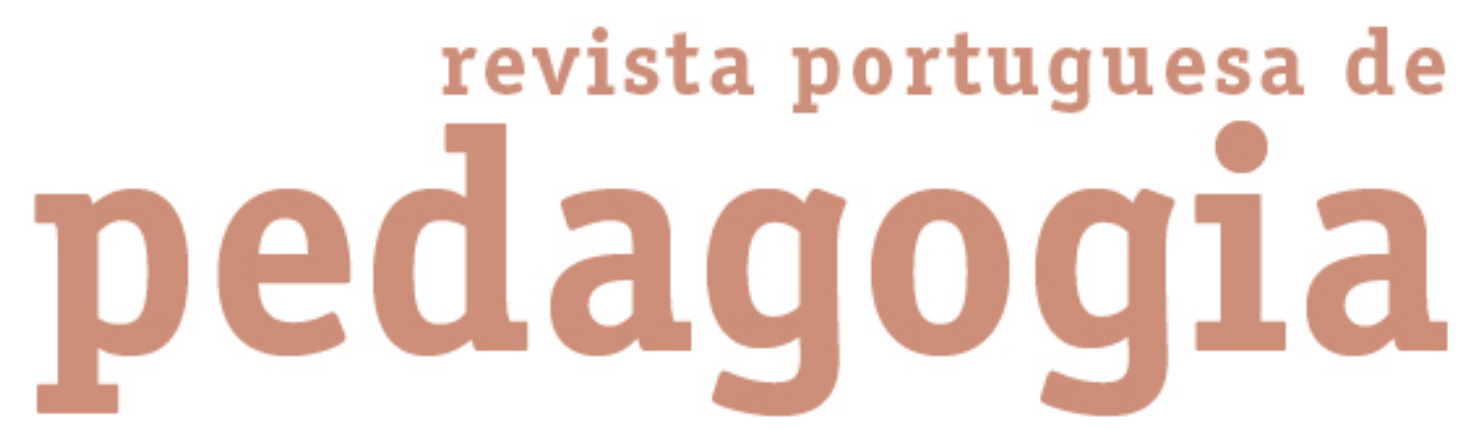

Diversificação, massificação e esvaziamento da oferta de educação e formação de adultos (EFA) em Portugal: algumas reflexões e inquietações
Autor(es):
Barros, Rosanna

Publicado por: Imprensa da Universidade de Coimbra

URL

persistente:

URI:http://hdl.handle.net/10316.2/40662

DOI:

DOI:https://doi.org/10.14195/1647-8614_50-1_1

Accessed : $\quad$ 26-Apr-2023 12:14:53

A navegação consulta e descarregamento dos títulos inseridos nas Bibliotecas Digitais UC Digitalis, UC Pombalina e UC Impactum, pressupõem a aceitação plena e sem reservas dos Termos e Condições de Uso destas Bibliotecas Digitais, disponíveis em https://digitalis.uc.pt/pt-pt/termos.

Conforme exposto nos referidos Termos e Condições de Uso, o descarregamento de títulos de acesso restrito requer uma licença válida de autorização devendo o utilizador aceder ao(s) documento(s) a partir de um endereço de IP da instituição detentora da supramencionada licença.

Ao utilizador é apenas permitido o descarregamento para uso pessoal, pelo que o emprego do(s) título(s) descarregado(s) para outro fim, designadamente comercial, carece de autorização do respetivo autor ou editor da obra.

Na medida em que todas as obras da UC Digitalis se encontram protegidas pelo Código do Direito de Autor e Direitos Conexos e demais legislação aplicável, toda a cópia, parcial ou total, deste documento, nos casos em que é legalmente admitida, deverá conter ou fazer-se acompanhar por este aviso. 


\section{revista portuguesa de pedagogia}

EDUCAÇÃO E FORMAÇÃO DE ADULTOS 


\title{
Diversificação, Massificação e Esvaziamento da Oferta de Educação e Formação de Adultos (EFA) em Portugal: Algumas Reflexões e Inquietações
}

\section{Rosanna Barros ${ }^{1}$}

\begin{abstract}
Resumo
Admitindo o Estado, nas suas várias reconfigurações hodiernas, como ator político principal no dever de zelar pela garantia e efetivação do direito dos adultos à educação, adota-se na análise uma ótica de justiça social que ultrapassa e torna dilemática a ótica de justiça de mercado. Com esta matriz de fundo reflete-se sobre as características, bem como ambivalências e tensões, tanto da agenda de diversificação como da agenda de massificação da Oferta Nacional de Educação e Formação de Adultos (EFA). Por fim, tecem-se reflexões sobre o momento político atual considerando que dados internacionais apontam agora Portugal como o último país da União Europeia quanto à Educação ao Longo da Vida dos adultos pouco escolarizados. Neste texto posicionamo-nos contra os traços neoliberais na governação hodierna do sector.

Palavras-chave: Educação e Formação de Adultos; políticas públicas; governação e agenda educacional
\end{abstract}

1 Professora Adjunta, Centro de Investigação em Espaços e Organizações (CIEO-Ualg), Universidade do Algarve. Email: rmbarros@ualg.pt 


\title{
Diversification, Massification and Depletion of the Portuguese Offer of Adult Education and Training: Reflexions and Anxieties
}

\begin{abstract}
:
Under the assumption that the "state" is the main political actor, in its various current reconfigurations, and has the duty to assure the right of adults to education, we will adopt a perspective of social justice that goes beyond and questions the perspective of justice induced by the market. Having this framework in mind, we will reflect on the features, as well as the various kinds of ambivalence and tension, both of the agenda concerning diversification and the one of the massification of the National Offer of Adult Education and Training (AET). Finally, we will make some considerations about the current political situation, taking into account the international data that point out Portugal as the last in the European Union rank concerning Lifelong Education of individuals with a low schooling level. In this article we position ourselves against the neo-liberal trends in the current governance of this area.
\end{abstract}

Keywords: Adult Education and Training; public policies; governance; educational agenda

\section{Diversificación, Masificación y Vaciamiento de la Oferta Nacional de Educación e Formación de Adultos (EFA): Algunas Reflexiones e Interrogantes}

\section{Resumen}

Admitimos que el Estado, en sus diversas reconfiguraciones actuales, es el actor principal en el deber de garantizar el derecho a la educación de las personas adultas, en una óptica de justicia social, que ultrapasa e hace dilemática la óptica de la justicia del mercado. Con esta matriz de fondo se reflecte sobre las características, ambivalencias y tensiones, tanto de la agenda de diversificación como de la agenda de masificación de la oferta de Educación e Formación de Adultos. Por fin, se reflexiona acerca del actual momento político en que los datos internacionales apuntan a Portugal como el último país de la Unión Europea cuanto a la educación a lo largo de la vida de las personas adultas con bajas cualificaciones. Terminamos tomando posición contra los trazos neoliberales de la gobernación hodierna del sector.

Palabras clave: Educación y Formación de Adultos; políticas públicas; gobernación y agenda educacional 


\section{Introdução}

Este artigo percorre o essencial do panorama referente à agenda educacional portuguesa para o sector da Educação e Formação de Adultos (EFA), sobretudo desde 1999, para refletir acerca da persistente ausência de uma Política de Educação de Adultos, que possa ser caracterizada simultaneamente, por ser pública, global, integrada, autónoma e democraticamente governada (Barros, 2013a; Lima, 2007; Melo, Lima, \& Almeida, 2002). Ou seja, este texto parte de um referencial teórico que convoca um conceito amplo de educação de adultos, que se inspira na proposta conceptual e de princípios orientadores defendidos pela Organização das Nações Unidas para a Educação, a Ciência e a Cultura (UNESCO) (avançada em Nairobi em 1976). Este referencial concebe a obrigação das políticas educativas salvaguardarem o direito à educação de adultos através da criação de um amplo leque de modalidades disponíveis (educação escolar: superior, alternância e alfabetização; formação profissional; extensão educativa e extraescolar; educação à distância; reconhecimento de adquiridos; animação comunitária; educação popular; desenvolvimento local, etc.). Com esta matriz exploraram-se as lógicas de (des)continuidade entre modalidades e níveis educacionais presentes na agenda nacional das políticas públicas deste sector.

Não obstante este mapa conceptual, assente em pressupostos do paradigma da educação permanente, estamos, também, cientes dos efeitos do atual horizonte de pressões que, a curto prazo, estão a operar importantes reconstruções de sentido nos conceitos fundadores deste campo educacional (Barros, 2011), como se percebe da própria ação do atual Instituto para a Aprendizagem ao Longo da Vida da UNESCO. Este, após as recomendações do Marco de Ação de Belém, resultante da última Conferência Internacional para a Educação de Adultos, CONFINTEA (em 2009), reviu recentemente a recomendação de Nairobi, à luz dos pressupostos do Acordo de Muscat (2014), recomendando agora, de modo mais genérico: uma abordagem da aprendizagem ao longo da vida capaz de conferir empowerment às pessoas para realizar o seu direito à educação, atingir as aspirações profissionais e contribuir para objetivos da comunidade envolvente; e de modo particular: ações para concretizar a literacia para os jovens e os adultos, nomeadamente desenvolvendo competências para o trabalho, a cidadania e o desenvolvimento sustentável.

Ora, face aos tempos de mudança nesta alvorada do século XXI, que se vem revelando como um cenário de crise, o nosso posicionamento tem sido o de considerar urgente ensaiar formas de restaurar, criticamente, as relações entre educação e cidadania social. Para o sector, trata-se de reconhecer, e reivindicar, a educação de adultos como um direito humano, o que implica considerar o Estado, nas suas várias reconfigurações hodiernas, como o ator político principal no dever de zelar pela garantia e efetivação 
deste direito, numa ótica de justiça social que ultrapassa e torna dilemática a ótica de justiça de mercado que tem vindo a dominar o campo das políticas educacionais.

Porém, e face, também, ao contexto de atual esvaziamento das ofertas nacionais de EFA, pareceu-nos pertinente convidar a refletir, neste texto, sobre que possibilidade há, hoje, de se reivindicar uma nova oportunidade para a educação de adultos, na medida em que o nosso olhar analítico é instigado pela ideia central de encarar a história como possibilidade, unindo esforços coletivamente para contrariar o atual recuo da democracia portuguesa que se observa, a partir da governação deste sector.

\section{Aspetos da agenda de diversificação da oferta de EFA}

Em vésperas da viragem do século, foi criado em Portugal um Grupo de Missão para o Desenvolvimento da EFA (GMEFA), incumbido de lançar um Projeto de Sociedade S@ ber+. Este GMEFA foi norteado por dois grandes objetivos: criar a Agência Nacional de Educação e Formação de Adultos (ANEFA) e colocar os alicerces de uma nova oferta, que se desejava mais acessível, flexível e adequada aos adultos pouco escolarizados do contexto nacional (Cavaco, 2009). Com efeito foi possível quer a criação, por um processo participado, da ANEFA (responsável por lançar, a partir de 2000, muitos e significativos programas e medidas para o sector); quer a articulação estratégica com as autarquias, escolas, parceiros sociais e entidades privadas visando a elaboração de planos e unidades territoriais de EFA; quer a organização e animação de uma rede nacional de animadores locais, e a construção experimental e gradual de um sistema de validação formal dos saberes e competências informais. Ora, a partir das dinâmicas suscitadas pelo GMEFA, iniciou-se efetivamente "a construção de um 3ํsector autónomo - mas complementar do sistema escolar de cursos noturnos e das ações de formação profissional - o sistema EFA, tão desescolarizado quanto possível" (Melo, 2001, p. 106).

O Programa de Ação S@ber+: Programa para o Desenvolvimento e Expansão da Educação e Formação de Adultos, 1999-2006, com que se iniciou a agenda do século $\mathrm{XXI}$, mais do que atualizar as propostas dos Documentos e Relatórios precedentes, apresentou e disseminou uma nova conceptualização do campo, que deixou oficialmente de ser de educação de adultos (EA) para passar a ser de educação e formação de adultos (EFA), entendendo-se por tal:

... o conjunto das intervenções que, pelo reforço e complementaridade sinérgica com as instituições e as iniciativas em curso no domínio da educação e da formação ao longo da vida, se destinam a elevar os níveis educativos e de qualificação da população adulta e a promover o desenvolvimento pessoal, a cidadania ativa e a empregabilidade. (Melo, Matos, \& Silva, 2001, p. 11), 
tendo sido declarado que a sua estratégia e sentido visavam "a promoção da articulação entre os domínios da educação, formação e emprego, através do reconhecimento dos processos de aprendizagem não formais, nomeadamente os ligados aos contextos de trabalho" (Trigo, 1999, p. 6).

Assim, o panorama da oferta nacional ficou ancorado aos pressupostos do Programa de Ação S@ber+que apresentou um conjunto diverso de finalidades e objetivos que enformaram a base dos princípios gerais para as medidas que coube depois à ANEFA executar. E, deste modo, a ANEFA foi criada para tutelar especificamente o sector, segundo três eixos de intervenção, designadamente: para desenvolver a motivação das pessoas adultas para a procura; para desenvolver uma oferta adequada, flexível e diversificada de educação e formação por parte das entidades formadoras; e para desenvolver a formação de agentes. Não deixa de ser interessante verificar, no âmbito dos eixos de intervenção contemplados neste Programa, a ambivalência resultante de o mesmo se apresentar formalmente como estando inscrito "no quadro da filosofia de cariz humanista" (Melo et al., 2001, p. 15), ao mesmo tempo que nele é significativa a valorização implícita de uma lógica de mercado que se traduz na promoção de atividades destinadas a motivar uma procura para satisfazer uma oferta.

Desta forma, no âmbito do primeiro eixo de intervenção, dirigido ao aumento da procura, a aposta seria feita numa forte e constante campanha de comunicação e na criação e apoio aos Clubes S@ber+ (cf. Melo et al., 2001, p. 29-32). Afigura-se-nos fundamental, neste ponto, enfatizar o paradoxo relacionado com o facto de que estes Clubes, que seriam "espaços de convívio, acolhimento, informação e orientação de adultos" (Melo et al., 2001, p. 30), e representariam o coração de um sistema EFA com possibilidades de escapar a uma mera instrumentalização do sector para benefício da economia, na realidade não chegaram a ser implementados consistentemente. No segundo eixo de intervenção, que pretendeu diversificar a oferta, a aposta surgiu maioritariamente orientada para a consolidação de um novo Sistema EFA de estrutura modelar centrado no reconhecimento, validação e certificação dos resultados da autoformação da população adulta, priorizando-se a criação das estruturas necessárias para permitir que os adquiridos informais fossem alvo de uma "análise rigorosa e reconhecimento formal, traduzidos numa validação oficial: creditação (outorga de créditos) com equivalência, parcial (dispensa de uma certa parte do percurso de formação) ou total (certificação, obtenção imediata de diploma oficial)" (Melo et al., 2001, p. 33). Por fim, o terceiro eixo de intervenção visou investir na "formação dos diferentes tipos de profissionais que serão responsáveis pela concretização do presente programa" (Melo et al., 2001, p. 39), agrupados em quatro categorias principais: os organizadores locais, os avaliadores de competências-chave, os formadores e os responsáveis dos Clubes S@ber+. 
Ora, nestes termos, e de um modo geral, previa-se para a implementação do Programa de Ação S@ber+ (1999-2006) um papel chave para a ANEFA, quer no incremento alargado de diversas parcerias com o terceiro sector, quer na promoção de múltiplas articulações com sistemas já existentes, tais como, o sistema de formação profissional, o sistema escolar e o sistema nacional de certificação. E foi, deste modo, que surgiu no panorama português uma tutela especializada, a ANEFA $^{2}$ que foi

concebida como estrutura de competência ao nível da conceção de metodologias de intervenção, da promoção de programas e projetos e do apoio a iniciativas da sociedade civil, no domínio da EFA, e ainda da construção gradual de um sistema de reconhecimento e validação das aprendizagens informais dos adultos. (DL n. 387/99)

Desta forma, tanto o ano de 2000 como o ano de 2001 foram marcados, em Portugal, pela entrada em cena do funcionamento da ANEFA, o que, segundo Santos Silva, representou "um passo qualitativo fundamental na reorganização da oferta pública numa matéria tão decisiva para o nosso futuro quanto a qualificação da nossa população ativa" (Silva, 2002, p. 67). Foram promovidas atividades que se destinaram, no essencial, a ir ao encontro da frágil situação educacional da população ativa ${ }^{3}$ mediante a "criação de soluções flexíveis que articulem a educação e a formação, através de percursos organizados, a partir de processos de reconhecimento e validação de saberes adquiridos e de sistemas modulares de formação" (ANEFA, 2001b, p. 29). A par do Ensino Recorrente de Adultos (ERA), básico e secundário, e da Educação Extraescolar (EEE), a estruturação da nova oferta de EFA compreendeu, a partir deste período, as seguintes modalidades: uma oferta de Cursos de Educação e Formação de Adultos (Cursos EFA); uma oferta de Ações S@ber+; e uma oferta de Reconhecimento, Validação e Certificação de Competências (RVCC). Pelo que, como resultado das políticas públicas efetivadas pela ANEFA (Lima, 2005; Rothes, 2009), se viria a constatar um real alargamento da rede nacional afeta ao sector, e portanto, antes de mais, uma expansão da diversificação da oferta, apesar da excessiva concentração de esforços numa parcela da população adulta: a população ativa.

2 Criada em Setembro de 1999 pelo Decreto-Lei n. 387/99, de 28/9.

3 É fundamentalmente a pensar apenas na parcela da população adulta portuguesa que era ativa, que se iriam desenvolver as novas atividades de EFA. Tratando-se de um universo de cerca de 4700000 de ativos em que, segundo dados do Ministério do Trabalho e Solidariedade de 1998, "cerca de 2400000 não possuem o 9ำ ano de escolaridade, sendo que $30 \%$ dos ativos são semi ou não qualificados, isto é, têm uma formação inferior ao nível III de qualificação profissional" (cf. ANEFA, 2001b, p. 29).

4 Note-se que, de acordo com os censos de 1991, cerca de 77 \% da população portuguesa não possuía, à data, a escolaridade de seis anos. Segundo as estatísticas demográficas gerais destes censos, o total da população residente em Portugal seria igual a 9853896 indivíduos. (cf. INE, 1993). Valor que passaria a ser de 10356117 indivíduos em 2001 (cf. INE, 2002). 
Posto isto, destacaremos, sucintamente, algumas das principais características de cada uma destas novas possibilidades referentes ao Sistema EFA. Assim, no respeitante à oferta de Cursos EFA ${ }^{5}$ o que sobressaiu como mais característico e inovador foi a sua conceção numa lógica de dupla certificação ${ }^{6}$, escolar e profissional, a partir de um modelo, que se queria integrado, baseado num Referencial de Competências-chave, e assente no princípio transversal de iniciar cada Curso EFA com base num reconhecimento e validação das competências (RVC) adquiridas previamente por cada adulto-formando ${ }^{7}$. Tratava-se, no essencial, de instituir um novo ponto de partida para os processos pedagógicos que envolviam os adultos, ambicionando-se superar "a dupla herança" (cf. Canário in ANEFA, 2002e, p. 50) que vinha caracterizando a história recente do sector em Portugal, nomeadamente a da vertente escolarizante que persistiu no ensino recorrente de adultos, e a vertente da formação profissional, tendente a reproduzir uma perspetiva funcionalista da relação entre a formação e o trabalho. De acordo com Canário,

estas duas tradições situam-se nos antípodas de uma formação que se pretende baseada na centralidade do sujeito que aprende, a partir do reconhecimento e validação de adquiridos experienciais e tendo como referência não uma listagem de conteúdos, mas sim um conjunto alargado de competências a construir. (Canário in ANEFA, 2002e, p. 50)

Neste sentido, toda a sua conceção curricular, inovadora no sector ${ }^{8}$, envolveu um sistema modular criado "numa perspetiva de individualização e diferenciação dos trajetos

\footnotetext{
5 Na justificação estratégica deste Cursos, apresentada no Plano de Atividades da ANEFA para 2001, pode ler-se: "A diversificação e a flexibilização das ofertas de educação e formação de adultos, sobretudo as destinadas à população com mais baixos níveis de qualificação escolar e profissional, mantem-se, em 2001, um imperativo que a ANEFA assume como uma das prioridades da sua intervenção (...) face à posição que Portugal ocupa relativamente aos restantes países da União Europeia no que concerne aos índices de escolarização e qualificação da sua população, e face, também, ao agravamento dessa posição nos últimos anos" (ANEFA, 2001a, p. 41).

6 Sendo estrategicamente assim, como se pode ler no Plano de Atividades da ANEFA para 2002, de modo a eficientemente "contribuir para a redução em simultâneo dos défices de qualificação escolar e profissional da população portuguesa" (ANEFA, 2002a, p. 35). Também o Relatório Nacional sobre os primeiros Cursos EFA em observação reitera este entendimento, sublinhando: "os Cursos EFA são, assim, um instrumento que tem por finalidade proporcionar a redução dos elevados índices de subqualificação escolar e profissional" (ANEFA, 2002e, p. 15). A dupla certificação é concebida nos termos do Despacho Conjunto n. 0 1083/2000, de 20 de Novembro.

7 A especificidade dos destinatários particularizaria esta oferta, concebendo-se para "adultos pouco qualificados, muitas vezes em risco de exclusão social, [cursos] numa perspetiva de construção de novas relações sociais, interativas e de empowerment, capazes de proporcionar a esses adultos a construção dos seus próprios projetos de vida pessoais e profissionais" (ANEFA, 2002e, p. 12)

8 Esta nova orientação metodológica para os Cursos EFA seria o resultado, afirma-se, da "procura de uma solução formativa efetivamente capaz de propor um modelo mais consentâneo com a natureza dos adultos
} 
de educação-formação, incluindo componentes integradas de formação profissionalizante e de formação de base que possibilitem a obtenção de uma certificação única" (ANEFA, 2002c, p. 7-8), num dos três níveis de certificação ${ }^{9}$ com que o Projeto-piloto dos Cursos EFA começaria por ser implementado no contexto português. O balanço público, resultante da análise dos primeiros 13 Cursos EFA em observação, foi apresentado, em 2002, como globalmente positivo encorajando "o alargamento e consolidação progressivos deste novo tipo de oferta educativa, dirigido a públicos adultos não escolarizados ou cuja escolarização não cobre a educação básica obrigatória" (Canário in ANEFA, 2002e, p. 49). No que respeitou à administração central desta nova oferta, destacou-se a adoção de um modelo que, de acordo com Trigo, "faz um convite e um apelo a todas as organizações da sociedade civil, acreditadas pelo INOFOR ${ }^{10}$, para desenvolverem Cursos EFA" (Trigo, 2002, p. 116), o que neste âmbito representou, sobretudo, a indução clara de novas formas de governação educacional no sector (Barros, 2009a; Jessop, 1998).

No referente, por seu turno, à oferta de Ações S@ber+, sobressaiu como mais característico a estrutura destas ações de formação de curta duração, que foram concebidas para abranger um vasto leque de domínios possíveis de formação, permitindo aos adultos usufruir de um ou mais módulos (de 50 horas cada) diferenciados entre si, por serem: de iniciação, de aprofundamento ou de consolidação de conhecimentos (cf. ANEFA, 2001b, p. 31). A sua criação serviu de suporte às restantes ofertas, visando atingir o objetivo de "desenvolver ou reforçar competências em domínios profissionais, escolares e pessoais" (ANEFA, 2001a, p. 45) e cumprir a estratégia geral afeta à criação do novo sistema EFA, designadamente: "promover a aprendizagem ao longo da vida, contribuindo para uma resposta eficaz às exigências da terciarização e do desenvolvimento económico" (ANEFA, 2002a, p. 37).

Por fim, no que diz respeito, por sua vez, à oferta de Reconhecimento, Validação e Certificação de Competências (RVCC), o que sobressaiu como mais característico foi, desde logo, o seu enquadramento numa estratégica que passou por assumir que "existe em Portugal uma subcertificação" (ANEFA, 2001b, p. 39), sendo por esta via justificada a criação de "duas grandes áreas de intervenção (...) [para] ser dada a oportunidade a todos os cidadãos, e, em particular, aos menos escolarizados e aos ativos empregados e

\footnotetext{
e de escapar à lógica escolar do currículo [pelo que] a ANEFA concebeu uma organização curricular pelas competências que, numa perspetiva mais ampla e englobante, devem ser entendidas como 'saberes em ação e para a ação'" (ANEFA, 2002d, p. 6).

9 No final do percurso formativo assim efetuado, foi possível em Portugal a obtenção de um Certificado de EFA, que no período entre 2001 e 2007 poderia ser de três tipos: Básico 1 (B1), equivalente ao 1 Ciclo do Ensino Básico e ao Nível I de Qualificação Profissional; Básico 2 (B2), equivalente ao 2 Ciclo do Ensino Básico e ao Nível I de Qualificação Profissional; ou Básico 3 (B3), equivalente ao 3 Ciclo do Ensino Básico e ao Nível II de Qualificação Profissional.

10 Instituto para a Inovação na Formação (INOFOR).
} 
desempregados, de verem reconhecidas e certificadas as competências e conhecimentos que, nos mais variados contextos, foram adquirindo ao longo do seu percurso de vida" (ANEFA, 2001a, p. 21). Foi arquitetado, por um lado, o Sistema de Reconhecimento, Validação e Certificação de Competências (Sistema RVCC) e, por outro lado, a construção de uma Rede de Centros de Reconhecimento, Validação e Certificação de Competências (a rede de Centros RVCC esteve vigente, com esta designação, entre 2001 e 2005).

Assim, segundo Santos Silva, a ANEFA regeu a sua intervenção com base no princípio de que "é possível e necessário valorizar a experiência e as capacidades profissionais, além de pessoais e cívicas, dos adultos para melhorar também o seu nível educacional" (Silva, 2002, p. 73), tendo sido as suas prioridades assegurar o desenvolvimento do essencial dos processos metodológicos inerentes ao Sistema RVCC, ou seja: quer as bases do modelo de organização e intervenção inerente ao processo RVCC; quer os materiais específicos de apoio ao desenvolvimento estrutural e organizacional das práticas (foi elaborado um kit para o processo RVCC); quer dos diversos instrumentos diretos de apoio para os profissionais de RVCC e para os adultos em processo; quer de dispositivos indiretos de apoio para uma documentação técnica/pedagógica adequada a todos os intervenientes no processo de RVCC; quer da compilação e divulgação de materiais de suporte teórico ao processo de balanço de competências e à construção do Dossier Pessoal (Portefólio) dos adultos. A sua atividade institucional neste domínio passou ainda por estabilizar os procedimentos relativos: ao registo nacional de avaliadores externos; à definição da gestão técnico-pedagógica dos Centros RVCC; e à acreditação de entidades potenciais promotoras de novos Centros RVCC. Ora, tudo isto foi feito com vista a conduzir, progressivamente, à consolidação futura do funcionamento nacional, que se pretendeu em rede e numa lógica de parcerias, dos Centros RVCC. O arranque efetivo desta nova oferta partiu do Projeto-piloto" ${ }^{11}$ que foi implementado, no contexto português, em torno de 6 Centros RVCC em observação ${ }^{12}$, tendo estes centros-piloto certificado pela primeira vez por esta via, cumulativamente entre si, um total de 493 adultos $^{13}$.

\footnotetext{
11 O Projeto-piloto de Centros RVCC consistiu no "lançamento 'em observação' dos primeiros Centros RVCC e envolveu diversas fases (estudo e conceção, produção de materiais, definição do modelo de formação e certificação dos profissionais de RVCC, negociação com parceiros, públicos e privados, obtenção atempada de financiamento) e culminou com uma sessão solene na Associação Comercial de Braga, no dia 11 de Dezembro, com a presença dos dois Ministros e respetivos Secretários de Estado que tutelam a ANEFA" (ANEFA, 2001b, p. 41). 12 As entidades promotoras dos seis primeiros Centros RVCC foram: no ano de 2000, a Associação Comercial de Braga; a Associação Nacional de Oficinas de Projeto (ANOP); o Centro de Formação Profissional do Seixal, e a Associação Nacional de Bombeiros; e no início de 2001, a Associação Industrial do Minho e a Agência para o Desenvolvimento do Alentejo Sudoeste (ESDIME).

13 De acordo com os indicadores de realização da ANEFA em 2001, estiveram inscritos 5804 adultos (3040 H e 2764 M), entrando em processo 1597 desses adultos (cf. ANEFA, 2002b).
} 
De sublinhar parece-nos ter sido o facto de que tendo esta oferta, em particular, sido inscrita numa linha de enfrentamento do problema da subcertificação, as orientações de política educativa teceram-se segundo linhas híbridas (Barros, 2014; 2013b) reconhecendo-se o potencial do processo RVCC para a "construção de oportunidades e percursos de formação congruentes com os trajetos e as aquisições passadas dos formandos" (Silva, 2002, p. 142), tendo-se afirmado a necessidade de evitar que esta oferta se transformasse numa "atribuição administrativa de títulos escolares" (Silva, 2002, p. 142) ao mesmo tempo que se redefiniram as metas físicas que cada Centro RVCC teria de cumprir, em termos de certificação, para tornar este investimento eficaz no objetivo de contribuir para "recuperar, tão depressa quanto possível, o atraso acumulado" (Silva, 2002, p. 141).

Posto isto, ficam mapeados alguns dos aspetos principais da estruturação nacional da nova oferta pública de EFA que contribuiu para a efetiva diversificação deste campo educacional no cenário português da alvorada do século XXI.

\section{Aspetos da agenda de massificação da oferta de EFA}

Em Portugal, o impacto da regulação supranacional da EFA tornou-se também explícito desde o Programa S@ber+,com base no qual se construiu a nova oferta pública de EFA, que representou o culminar de um emblemático processo político (Barros, 2012), porque atravessado por vincadas tensões, de construção nacional do subsistema educativo destinado aos adultos. Este, a partir de 2006, passa a ser caracterizado por uma lógica de massificação, assente na apresentação inexorável de resultados "no momento e num tempo em que todos falamos e debatemos o Memorando da União Europeia sobre Aprendizagem ao Longo da Vida" (Trigo, 2001, p. 106).

Efetivamente, em contexto nacional, e durante o curto interregno que ocorreria entre 2002 e 2005 do ciclo de governação socialista, a que correspondeu o XV e o XVI Governos constitucionais, quer as tendências de europeização das políticas públicas (Antunes, 2001; 2004) quer as tendências de subordinação a lógicas vocacionalistas (Antunes, 2011; Guimarães, 2011) na governação educacional pluriescalar do sector da EFA, não só teriam ambas prossecução como seriam inclusivamente radicalizadas (Barros, 2009b), sendo possível identificar uma assumida viragem na agenda para se enveredar por um novo mandato abertamente vocacionalista, que foi efetivado pelo Despacho 21974/2002 de 25 de Setembro e pelo Decreto-Lei 208/2002 de 17 de Outubro através dos quais se extinguiu a ANEFA e se integraram as suas funções no âmbito de uma nova Direção Geral de Formação Vocacional (DGFV). Desde então, o sector perdeu, de novo, a autonomia e especificidade que tinha sido 
alcançado na esfera pública estatal. Os principais documentos de política educativa (nacional e supranacional) para o sector, produzidos neste período, inscreveram-se, de forma clara, nas perspetivas de modernização que são, no contexto deste padrão contábil de governação educacional, radicalizadas, como aponta Lima, “já não apenas numa lógica gerencial e eficientista, mas também na perspetiva mais ampla de uma reforma do Estado, numa lógica de mercado e de subordinação da educação a orientações pragmáticas, de empregabilidade, de emulação e competitividade económica" (Lima, 2005, p. 49).

Assim, foram, por exemplo, iniciados nesta altura, e com este enquadramento, os procedimentos conducentes a uma nova revisão ${ }^{14}$ da Lei de Bases do Sistema Educativo (LBSE), e a uma reforma do ensino recorrente de adultos ${ }^{15}$ (a oferta mais antiga e a única com expressão até à criação e implementação do Programa S@ber+), tendo sido lançado para discussão pública, em 2003, o Documento Orientador da Revisão Curricular do Ensino Secundário Recorrente. Neste assumiu-se a valorização do sector "como contributo decisivo para a concretização do objetivo estratégico de qualificação dos portugueses, bem como a concretização do desígnio europeu de uma efetiva e generalizada aprendizagem ao longo da vida" (Ministério da Educação, 2003, p. 2), explicitando-se ainda que, no fundo, se tratava de "proporcionar a todos o benefício da adaptação às exigências das mutações sociais e económicas" (Ministério da Educação, 2003, p 8). A merecer destaque surge a reconversão da lógica com que vinha sendo implementado o sistema de reconhecimento, validação e certificação de competências (Sistema RVCC), percecionado como "uma iniciativa - não apenas inovadora (no contexto europeu) - mas também pertinente e com espaço próprio no âmbito das políticas educativas, de emprego e de inserção social (...) [isto é] enquanto política ativa de emprego" (DGFV, 2004, p. 1; p. 61).

Estes exemplos ilustram, fundamentalmente, a pertinência de considerar a agenda nacional das políticas educacionais como globalmente estruturada (Dale, 2005), observando-se que a mesma passará a desenrolar-se, desde então, sempre em consonância com as dinâmicas supranacionais de europeização, como se pode comprovar para este curto período, pela influência e centralidade quer do Relatório de Base de Portugal sobre a realização das estratégias de educação e formação ao

14 Que seria aprovada na legislatura seguinte, originando a Lei no 49/2005 de 30 de Agosto.

15 Enquadrou-se a reforma do ensino recorrente de adultos (ERA) à luz do paradigma da aprendizagem ao longo da vida, sublinhando o seu contributo para a alteração da situação educacional da população adulta portuguesa, acerca da qual se destaca: "a baixa taxa de escolarização e os índices de abandono que se elevam além das médias europeias" (Ministério da Educação, 2003, p. 8). Note-se que o ensino recorrente secundário de adultos tinha já conhecido algumas inovações desde a alteração à LBSE de 1997 (Lei 115/97 de 19 de Setembro), consistindo na introdução: das unidades capitalizáveis em 1996/1997, dos blocos capitalizáveis em 1999/2000, e dos blocos de aprendizagem em 2004/2005. 
longo da vida na Europa, realizado em 2003 pela Comissão Europeia, quer mesmo do Relatório de Base de Portugal sobre os sistemas de qualificação e o seu impacto na aprendizagem ao longo da vida, elaborado no mesmo ano pela Organização para a Cooperação e Desenvolvimento Económico (OCDE). De ambos os relatórios resulta clara a crescente concretização da regulação supranacional da EFA, tendencialmente baseada na avaliação de resultados (economicamente) significativos.

O novo ciclo de governação política (partido socialista), vigente entre 2005 e 2011 com os XVII e XVIII Governos constitucionais, centrou a sua ação governativa em instituir uma nova velocidade e ritmo à implementação deste novo processo político de governação educacional balizado, primeiro, pela Agenda/Estratégia de Lisboa, nascida no Conselho Europeu da primavera de 2000, e posteriormente, pelo assumido relançamento da mesma, que saiu visivelmente reforçada do Conselho Europeu da primavera de 2005. Apesar de a relação entre o global e o local ser complexa (Fragoso, Kurantowicz, \& Lucio-Villegas, 2011), e não determinística no que concerne à emergência de dinâmicas nacionais decorrentes da nova governação pluriescalar do sector (Milana, 2015), o facto é que se acentuaram em Portugal, neste período, as políticas de racionalização (Barros, 2012; 2013a), típicas do padrão de governação educacional prevalecente a nível supranacional (de tipo neoliberal). É possível identificar nos novos instrumentos de governação, tanto nos de planeamento como nos de orientação e de concertação social, discursos consonantes com o novo gerencialismo que vem enformando, desde então, a elaboração de políticas, apontando para duas vertentes principais, designadamente: para a ideia explícita de moralizar o sistema educacional, que para o sector assentou sobretudo na promoção da igualdade de oportunidades, fomentada, segundo amplamente se publicitou, pela criação de novas oportunidades; e para a ideia implícita de promover o controlo social, que para o sector assentou na ideia da responsabilização individual pela empregabilidade através de mais educação e formação, de preferência ao longo de toda a vida, e em todos os lugares da vida. Tratou-se, na essência, de um novo processo político que se materializou através de uma significativa proliferação de novos instrumentos nacionais de governação reportáveis, por seu turno, a outros instrumentos transnacionais, tendo contribuindo ambos para confirmar a hipótese, avançada por Leibfried e Pierson (1995) da emergência progressiva na modernidade tardia de um sistema político de múltiplos níveis.

Com base neste quadro teórico-conceptual, a Iniciativa Novas Oportunidades ${ }^{16}$ (INO) surge como um instrumento de síntese, ou seja, representando um elemento paradigmático na governação educacional pluriescalar para o sector da EFA. Após a

16 A INO foi apresentada no debate mensal da Assembleia da República a 21 de Setembro de 2005. 
reconversão ${ }^{17}$ da Direção Geral de Formação Vocacional (DGFV) na Agência Nacional de Qualificação (ANQ), esta foi a entidade responsável pela coordenação, a nível nacional, da implementação generalizada a nível subnacional da INO. No essencial, esta iniciativa foi politicamente assumida como "um novo impulso no caminho da qualificação dos portugueses", tendo-se também sublinhando que o seu principal objetivo era o da "escolarização geral da população ao nível do ensino secundário", isto na medida explícita em que "a importância de apostar na generalização do nível secundário de escolaridade é claramente assumida pela Comissão Europeia" (cf. INO, 2005). Assim sendo, a estratégia da INO retomou e aprofundou as inovações de maior execução e financiamento introduzidas pelo Programa s@ber+, e assentou em dois pilares fundamentais, por um lado, na ideia de dar oportunidades novas aos jovens através do incremento de cursos técnicos e profissionais ${ }^{18}$ e, por outro lado, na ideia de dar uma nova oportunidade aos adultos ativos através do aumento dos Cursos EFA e do Processo de RVCC. Para ambos os eixos, foram estabelecidas metas concretas a atingir anualmente em cada um dos Centros Novas Oportunidades (CNO) da rede nacional ${ }^{19}$.

No âmbito da apresentação pública da INO chamou-se a atenção para o facto de, à data, a média de anos de escolarização em Portugal se situar nos 8.2 anos, enquanto, por exemplo, na Alemanha era de 13.4 anos e na Dinamarca de 13.6 anos (cf. OECD, 2005). De entre as doze medidas desta iniciativa, no eixo que se refere aos adultos ativos, destacamos a efetiva expansão da oferta deste sector a nível territorial, neste caso quer a oferta de Cursos EFA quer a oferta de Centros de RVCC, aumentando também para o 12 ano (a partir de 2007) o nível de formação e certificação obtido por estas vias. Assim, o conjunto de orientações, com destaque para a massificação da certificação, que caracterizaram a INO, surgiu justificado por um discurso onde era afirmado que "temos de fazer mais, temos de fazer melhor e temos de fazer mais rápido. Precisamos de acelerar fortemente a qualificação dos portugueses, tendo em vista a convergência com os países mais desenvolvidos" (cf. INO, 2005). E, neste contexto, sobressai o peso significativo que foi atribuído ao

\footnotetext{
17 Dando sequência à RCM № 124/2005, de 4 de Agosto, em que o 17o Governo constitucional lança o Programa de Reestruturação da Administração Central do Estado (Programa PRACE), o Decreto-lei n.응 213/2006, de 27 de Outubro, institui a nova Agência Nacional para a Qualificação, I. P., como "organismo sob superintendência e tutela conjuntas dos membros do Governo responsáveis pelas áreas da educação e do emprego e formação profissional" (cf. art.․ 5).

18 Designadamente: Cursos Tecnológicos; Cursos Profissionais; Cursos de Aprendizagem; Cursos de Educação e Formação; Cursos de Ensino Artístico; e Cursos de Especialização Tecnológica.

19 A designação de Centros Novas Oportunidades (CNO) veio substituir a designação anterior (Centros RVCC). Esta rede nacional de CNO esteve em funcionamento entre 2006 e 2012 e atingiu cerca de 500 estruturas com cobertura em todo o território nacional.
} 
Processo RVCC, com vista a reconhecer e validar as aprendizagens adquiridas ao longo da vida e nos seus diversos contextos, no âmbito de uma aposta nacional em prol da inclusão plena de Portugal na ambicionada "economia mais competitiva do mundo", como repetidamente se afirma nos diversos instrumentos de regulação supranacional, encontrando-se, de resto, esta opção inscrita, de acordo com Ana Luísa Pires, numa "convergência de preocupações, comuns a um conjunto significativo de países no espaço europeu e no mundo (...) [que inscrevem] o reconhecimento e a validação num paradigma de aprendizagem ao longo da vida" (Pires, 2007, p. 1). Com efeito, disseminou-se amplamente a ideia da aposta numa ambiciosa finalidade política de envolver 1000000 de jovens e adultos nas ofertas de EFA. Se entre 2000-2005 estiveram no total inscritos 153719 adultos neste processo, no período compreendido entre 2006-2010, estiveram no total inscritos 1163236 adultos (cf. CNE, 2011). Portanto, a INO traduziu-se, de facto, num aumento acentuado do acesso à EFA, com a inscrição expressiva de mais de 10\% da população portuguesa, como alguns estudos de avaliação demostraram (Carneiro, 2011; Liz, Machado, \& Burnay, 2009). Frequentadas por grupos heterogéneos, e integrando propostas de educação e formação que acentuaram a individualização dos processos, estas ofertas permitiram que, entre 2000 e 2010, 386463 indivíduos fossem certificados, para o caso do RVCC (sobretudo de certificação escolar, dado que o processo de qualificação profissional através desta oferta foi residual), e 68255 para os Cursos EFA (cf. ANQ, 2011).

Ora, não estando em causa o potencial do reconhecimento, validação, e mesmo certificação, dos adquiridos experienciais da população adulta (Barros, 2009b), várias análises críticas, como, por exemplo, a de Rodrigues e Nóvoa, alertaram à época para "um pensamento 'mágico' ou administrativo que, por vezes, lhe surge associado" (Rodrigues \& Nóvoa, 2005, p. 11), ou seja, surgiram diversos estudos oriundos da academia que recomendavam quebrar com a lógica paliativa com que as ofertas de EFA estavam a ser concebidas (Cavaco, Lafont, \& Pariat, 2014; Lima, 2014; Marques, 2014) no âmbito do novo paradigma das políticas para as estatísticas.

\section{Aspetos da agenda de esvaziamento da oferta de EFA}

Se, mesmo após a real diversificação da oferta de EFA, e da sua (dilemática) massificação, atendermos às especificidades da formação social portuguesa e da presente situação educacional da sua população adulta (que prevalece preocupante), então, não se poderá ignorar, como sublinhou Licínio Lima, que "talvez um dos problemas do século XX tenha sido (e esteja a ser) o não cumprimento das velhas oportunida- 
des, das velhas promessas da modernidade, em termos de democratização, acesso à educação e intervenção social" (Lima, 1998, p. 19).

Ora, esta afirmação nos parece muito atual, sobretudo quando se observa a ação política do XIX Governo constitucional, vigente entre 2011 e 2015, que reduziu a governação educacional para este sector, sobretudo, à ação de suspender bruscamente os Cursos EFA e o Sistema RVCC que vinham sendo frequentados e concluídos por um número expressivo de adultos, permitindo assim a obtenção de valores relativos à participação em atividades de educação elevados para o contexto português (Benavente \& Peixoto, 2015), e, consequentemente, permitindo também a contratação de aproximadamente 10000 educadores de adultos que estiveram ligados, entre outras entidades, aos Centros Novas Oportunidades (cf. ANQ, 2011). Porém, no momento hodierno, em resultado da suspensão da "nova" política de EFA, efetuada entre 2012 e 2013, pouquíssimas ofertas de educação, pensadas para os adultos, podem ser encontradas neste país, no qual parece simplesmente ter deixado de haver lugar quer para educandos adultos pouco escolarizados, remetidos para fora do sistema de educação ${ }^{20}$, quer para os referidos educadores de adultos, remetidos para o desemprego (senão para a emigração), não obstante a sua autoformação especializada, que constitui um manancial de aprendizagem experiencial nunca antes atingido, na mesma proporção, pelos profissionais da área (Loureiro \& Caria, 2013) e, hoje, em risco de volatilização no âmbito do recente e radical esvaziamento da agenda educacional para a EFA.

Por um lado, seguindo-se a tradicional lógica nacional de reconversão institucional no âmbito da administração central da educação de adultos, a Agência Nacional para a Qualificação (ANQ) daria lugar, em 2012, à Agência Nacional para a Qualificação e o Ensino Profissional ${ }^{21}$ (ANQEP), com a missão de coordenar a execução das políticas de educação e formação profissional de jovens e adultos. Uma reconversão, de resto operada, sem comprometer o mandato, também tradicionalmente vocacionalista, que vem caracterizando a história portuguesa deste sector. Também a bem da continuidade da descontinuidade, que se vem revelando uma invariante estrutural da governação da educação de adultos em contexto nacional (Lima, 2007), a Rede de CNO foi desmantelada, emergindo, em 2013, uma nova Rede, comparativamente muito mais reduzida, de Centros de Qualificação e Ensino Profissional (Rede de (QEP), definindo-se, normativamente, como âmbito da sua intervenção a "informação, orientação e encaminhamento de jovens e de adultos que procurem uma

20 No ano letivo 2012/2013 o total de adultos envolvidos em atividades de EFA, em todos os ciclos de ensino (do nível básico e secundário), foi de 87 265, enquanto no ano letivo 2010/2011 foi de 305860 (dados consultados em http://www.dgeec.mec.pt).

21 Decreto-Lei n. 36/2012, de 15 de fevereiro. 
formação escolar, profissional ou de dupla certificação e/ou visem uma integração qualificada no mercado de emprego"22, encaminhando jovens a partir dos 15 anos de idade para ofertas de formação.

Por outro lado, a anterior governação educacional para este sector ( XIX Governo Constitucional) decidiu voltar ao ensino recorrente de adultos (ERA) como resposta para quem procura continuar a sua trajetória escolar. Trata-se de uma opção difícil de compreender do ponto de vista da teoria educacional e pedagógica, ou da andragogia se se preferir, dado que inúmeros estudos, oficiais e académicos, existentes nesta matéria (tanto a nível nacional como internacional), demonstraram que a escolarização da educação de adultos the retira o potencial transformador, sendo essencial a incursão nas lógicas da educação não-formal e informal, quer para os educandos quer para os educadores de adultos, cuja formação profissional precisa ser especializada, contínua e continuada (Bengtsson, 1989; Esteves, 1996; Lazarus, 1989; Rothes, Silva, Guimarães, Sancho, \& Rocha, 2006). A não ser assim, o que se sabe está largamente explanado nas estatísticas da época em que o ERA se apresentava praticamente como a única oferta ao nível das políticas públicas nacionais e vigorava quase sempre desprovido de lógicas que permitissem ultrapassar os muros da escola (cf. CNE, 1990), nomeadamente: na sua taxa de abandono elevadíssima, onde menos de $4 \%$ terminavam os graus de escolaridade iniciados e havia zonas do país que não atingiam 1\% (cf. Pinto, Matos, \& Rothes, 1998). Portanto, a opção não é científico-pedagogicamente fundada, tal como o não é a convicção de que só os exames confirmam as aprendizagens. Um pressuposto que, na nova Rede de CQEP, parece estar patente no, por sua vez renovado (desvirtuado?), processo de reconhecimento de adquiridos experienciais posto em curso, tratando-se, desde logo, de uma perspetiva paradoxal, que atribui um peso maioritário a uma prova/ exame com incidência em conhecimentos de conteúdos, ficando o restante peso pendente da validação do Dossier Pessoal (Portefólio) dos adultos.

Se oPrograma S@ber+diversificou a oferta nacional de EFA e a INO a massificou, o nome da linha programática que a fez implodir não é conhecido, mas vem sendo sentido, na medida em que, cada vez que se prolonga a escolaridade obrigatória (agora consagrada até ao 12ำ ano), criam-se exclusões em relação aos mais velhos, pouco escolarizados, quando na sua condição de pais, influenciam nos resultados escolares dos mais novos. Como a sociologia da educação demonstrou, também através de inúmeros estudos realizados em diversas geografias, as expectativas, os hábitos culturais, as relações com a escola estão profundamente marcadas pelo meio social e pelo grau de escolarização e de literacia dos pais, e de outros

22 Cf. Portaria no 135-A/2013, de 28 de março. 
adultos de referência, nas diversas comunidades em que vivemos (Benavente, 1991; Cortezão, 2000; Salgado, 2011).

Por fim, na conjuntura contemporânea, criada no âmbito da governação pluriescalar do sector da EFA pelo paradigma hegemónico da política pública para as estatísticas, é também paradoxal a variedade de sentidos que se poderiam retirar do facto contábil de Portugal ter sido posicionado, em 2010, pelo Centro Europeu para o Desenvolvimento da Formação Profissional (CEDEFOP), entre os três países mais "avançados" da Europa na implementação de sistemas nacionais de adquiridos experienciais (a par da França e da Noruega), onde integrava a categoria 1, dos países que "estabeleceram práticas de validação, abarcando todos ou a maior parte dos sectores de aprendizagem e que demonstram já um nível significativo de certificações por esta via", aparecendo ali valorizado, também, o "carácter claramente inovador" do Sistema RVCC face ao conjunto dos países europeus (cf. CEDEFOP, 2010). Isto quando comparado com dados da mesma Instância Internacional, de 2015, que apontam agora Portugal como o último país da União Europeia quanto à Educação ao Longo da Vida dos adultos pouco escolarizados (cf. CEDEFOP, 2015).

\section{Traços marcantes do desenvolvimento hodierno do sector}

As marcas sociopolíticas deixadas na formação social portuguesa para o início do século XXI tiveram a assumida pretensão de instituir um novo contrato social em torno da ideia da aprendizagem ao longo da vida. Este facto revelar-se-ia ser não só estratégico para os desenvolvimentos subsequentes a nível da consolidação de uma nova lógica nas modalidades de provisão educativa para adultos como, inclusive, permitiria legitimar uma mais vasta reformulação do papel do Estado de bem-estar na área da produção das políticas sociais, através da efetivação do modelo do partenariado social (Antunes, 2001, 2004).

Ora, sendo Portugal um país da semiperiferia europeia caracterizado, no essencial, por deter um Estado forte e centralizado, um mercado fraco e díspar, e uma sociedade civil simultaneamente forte na provisão social compensatória e fraca na sua organização cívico-política reivindicativa (Santos, 1998), a nova combinação institucional assente na figura do partenariado, que foi avançado como sinónimo de participação (Antunes, 1998), foi construída com uma dupla finalidade. Por um lado, a de legitimar no sistema político os projetos centrais, neste caso de índole educacional, mediante a sua assunção (pretensamente democrática) por parte de organizações e instituições periféricas da sociedade civil e, por outro lado, a de contribuir para substituir a conflitualidade de interesses plurais por uma negociação 
cooperante, neste sentido habilitando-nos a compreender os motivos pelos quais "o partenariado socioeducativo surge como uma estratégia (instrumento) de cooperação numa perspetiva sistémica de relação sistema educativo/sistema económico e social" (Marques, 1994, p. 50).

De facto, seria esta a lógica que caracterizaria a nova forma de governação educacional da EFA que, a nível nacional, assentou na ideia estruturante de que o papel do Estado na modernização do país consistiria, sobretudo, em promover a criação de "operadores estratégicos de formação" (cf. Mesquita, 2000). Assim, o Estado capitalista democrático português assumiu-se (embora seguindo linhas de orientação ideológica híbridas entre um padrão humanista e um padrão neoliberal) como Estado articulador (Santos, 1998) de uma crescente rede de entidades promotoras de EFA criadas, como vimos, por mediação da ANEFA e massificadas, a partir de 2006, através da INO. Deste modo, as tensões próprias dos Estados Capitalistas Democráticos (Offe, 1984) parecem ter sido confrontadas pelo Estado semiperiférico português segundo um modelo contraditório que, de um lado, encarou e assumiu a necessidade de relançar e expandir um sector educativo excessivamente afunilado e, de outro lado, anuiu na prioridade à competitividade nacional e aos requisitos necessários à adoção europeia de um novo modelo de desenvolvimento económico.

É visível, desde o início do milénio, neste cenário nacional de políticas de EFA que os novos instrumentos comuns de governação para o Espaço Europeu de Educação e Formação foram bem-sucedidos a criar e potenciar uma nova ordem educacional (Field, 2002), caracterizada pela eficiência da 'nova administração pública', que em Portugal e em pouco tempo, certificou, de facto, um número significativo de adultos ao nível da escolaridade básica e secundária. Aparentemente ficou cumprido o programa INO justificando-se assim, por um lado, para o XIX Governo (Partido Social Democrata), o desmantelamento em 2012 da rede existente, e o redireccionamento da oferta para uma amostra nacional residual (e diluída) inscrita, desde 2013, nos novos CQEP.

Resta porém saber, por outro lado, se a obtenção de certificação escolar foi substantiva para a vida dos adultos envolvidos originando, ou não, transições com efeitos positivos nos seus cursos de vida (Ecclestone, 2009) e, na medida em que, como refere Seixas (2003), a lógica de organização do secundário parece constituir uma variável importante para a procura do ensino superior, haverá que desenvolver mais investigação para compreender melhor o impacto, nestes adultos, da valorização das aprendizagens experienciais no âmbito da conclusão dos estudos secundários com opção associada de continuidade de estudos no âmbito do ensino superior. 


\section{Apontamento crítico final em tempos incertos de mudança}

É ainda demasiado cedo para perceber o sentido que a ação política do XXI Governo constitucional, vigente desde 2015, irá imprimir nas políticas públicas e no desenvolvimento do sector a partir de agora. Porém, se nos questionarmos, à luz da tradição crítica e emancipatória do paradigma da educação permanente, como faz Paula Guimarães, acerca do problema fundamental do nosso tempo, que é o de saber se

haverá lugar para a educação de adultos (enquanto recurso coletivo de mudança social e política no interesse de todos e sobretudo daqueles que têm menos poder e se encontram em ou mais perto de situações de marginalização e exclusão) na atualidade (e ao longo do séc. XXI)? Guimarães, 2008, p. 1,

então, teremos de admitir o desafio e a responsabilidade de, enquanto investigadores, indagarmos também pelo nosso papel e pelo papel dos atores da EFA, na subscrição ou recusa desta nova ordem educacional.

Dito de outra forma, e não obstante a complexidade envolvida na governação hodierna das políticas públicas, observar que todas estas novas orientações para a EFA têm vindo a ser apresentadas como acontecimentos consumados e, cada vez mais, como disrupções das agendas políticas anteriores para o sector, impõe, quer aos intelectuais orgânicos da academia quer aos atores das comunidades de práticas deste campo educacional, várias responsabilidades. De entre estas, destacam-se a responsabilidade de conhecer para agir, de denunciar para anunciar, de educar para conscientizar, e porque não, também a de ousar usar o discurso público ao seu alcance para contrariar uma perspetiva elitista da educação que parece obedecer a um certo 'mito do eterno retorno', ignorando, repetidamente, a larga maioria da população adulta deste país cuja educação de base está, por conseguinte, ainda claramente por consolidar.

\section{Referências bibliográficas}

ANEFA (2001a). Plano de atividades 2001. Lisboa: ANEFA.

ANEFA (2001b). Relatório de atividades 2000. Lisboa: ANEFA.

ANEFA (2002a). Plano de atividades 2002. Lisboa: ANEFA.

ANEFA (2002b). Principais indicadores de realização. Lisboa: ANEFA.

ANEFA (2002c). Cursos de educação e formação de adultos: Documento de trabalho. Lisboa: ANEFA.

ANEFA (2002d). Cursos de educação e formação de adultos: O modelo de intervenção (B2A). Lisboa: ANEFA.

ANEFA (2002e). Relatório nacional: Cursos de educação e formação de adultos "Em observação" 2000/2001. Lisboa: ANEFA. 
ANQ (2011). Linhas orientadoras para o futuro da iniciativa novas oportunidades. Lisboa: Agência Nacional para a Qualificação.

Antunes, F. (1998). Políticas educativas para Portugal, anos 80-90: O debate acerca do ensino profissional na escola pública. Lisboa: Instituto de Inovação Educacional.

Antunes, F. (2001). Os locais das escolas profissionais: Novos papéis para o Estado e a europeização das políticas educativas. In S. Stoer, L. Cortesão, \& J. A. Correia (Org.), Transnacionalização da educação: Da crise da educação à educação da crise, (pp. 163-208). Porto: Afrontamento.

Antunes, F. (2004). Globalização, europeização e especificidade educativa portuguesa: A estruturação global de uma inovação nacional. Revista Crítica de Ciências Sociais, 70, 101-125. Consultado em http://www.ces.uc.pt/publicacoes/rccs/ artigos/70/RCCS70-Fatima\%20Antunes-101-125.pdf

Antunes, F. (2011). Governação, reformas do Estado e políticas de educação de adultos em Portugal: Pressões globais e especificidades nacionais, tensões e ambivalências. Revista Crítica de Ciências Sociais, 92, 3-29. doi: 10.4000/rccs.3861

Barros, R. (2009a). Subsídios para a construção de um racional teórico para investigar os (novos) modos de governação e regulação das políticas educativas no sector da educação de adultos em Portugal. In H. Ferreira, C. Lima, F. Alves, G. Santos, \& S. Bergano (Orgs.), Atas do X Congresso da Sociedade Portuguesa de Ciências da Educação (SPCE): Investigar, avaliar, descentralizar. Bragança: Instituto Politécnico de Bragança.

Barros, R. (2009b). Políticas para a educação de adultos em Portugal: A governação pluriescalar da «Nova Educação e Formação de Adultos» (1996-2006) (Tese de doutoramento não publicada). Universidade do Minho, Braga.

Barros, R. (2011). Genealogia dos conceitos em educação de adultos: Da educação permanente à aprendizagem ao longo da vida - Um estudo sobre os fundamentos político-pedagógicos da prática educacional. Lisboa: Chiado Editora.

Barros, R. (2012). From lifelong education to lifelong learning: Discussion of some effects of today's neoliberal policies. RELA - European Journal for Research on the Education and Learning of Adults, 3(2), 119-134. doi: 10.3384/rela.2000-7426.rela0071

Barros, R. (2013a). As políticas educativas para o sector da educação de adultos em Portugal: As novas instituições e processos educativos emergentes entre 1996-2006. Lisboa: Chiado Editora.

Barros, R. (2013b). The Portuguese case of RPL new practices and new adult educators: Some tensions and ambivalences in the framework of new public policies. IJLE - International Journal of Lifelong Education, 32(4), 430-446. doi: 10.1080/02601370.2013.778071

Barros, R. (2014). The Portuguese recognition of prior learning (RPL) policy agenda: Examining a volatile panacea by means of ethno-phenomenological interpretations. Encyclopaideia, Journal of Phenomenology and Education, XVIII(40), 53-68. doi: 10.6092/issn.1825-8670/4653

Benavente, A. (1991). Do outro lado da escola. Lisboa: Editorial Teorema.

Benavente, A., \& Peixoto, P. (2015). Menos estado social, uma escola mais desigual. Lisboa: Observatório de Políticas de Educação e Formação/UC-ULHT. 
Bengtsson, J. (1989). Recurrent education. In C. J. Titmus (Ed.), Lifelong education for adults: An international handbook (pp. 43-51). England: Pergamon.

Carneiro, R. (2011). (Ed.). Accreditation of prior learning as a lever for lifelong learning: Lessons learnt from the New Opportunities Initiative, Portugal. Braga: UNESCO/MENON Network/CEPCEP, Centro de Estudos dos Povos e Culturas de Expressão Portuguesa - Universidade Católica Portuguesa. Consultado em http://www. ucp.pt/site/resources/documents/CEPCEP/Accreditation_final.pdf

Cavaco, C. (2009). Adultos pouco escolarizados: Políticas e práticas de formação. Lisboa: Educa. Cavaco, C., Lafont, P., \& Pariat, M. (2014). Policies of adult education in Portugal and France: The European agenda of validation of non-formal and informal learning. International Journal of Lifelong Education, 33(3), 343-361. doi: 10.1080/02601370.2014.896086

Cedefop (2010). Skills supply and demand in Europe: Medium-term forecast up to 2020. Luxembourg: Publications Office of the European Union.

Cedefop (2015). Work programme 2015. Luxembourg: Publications Office of the European Union.

CNE (1990). Educação de adultos: Ensino recorrente e educação extra-escolar. (Parecer no 2/90, redigido por Maria Teresa Ambrósio). In Conselho Nacional de Educação, Pareceres e Recomendações. Lisboa: CNE/Ministério da Educação.

CNE (2011). Estado da educação 2011: A qualificação dos Portugueses. Lisboa: Conselho Nacional de Educação/Ministério da Educação.

Cortezão, L. (2000). Escola, sociedade. Que relação? Porto: Edições Afrontamento.

Dale, R. (2005). A globalização e a reavaliação da governação educacional: Um caso de ectopia sociológica. In A. Teodoro \& C. A. Torres (Org.), Educação crítica e utopia: Perspetivas para o Século XXI (pp. 53-69). Porto: Edições Afrontamento.

Decreto-Lei n. 36/2012 de 15 de fevereiro. Diário da República - I Série, n. 33. Consultado em https://dre.pt/application/file/542957

Decreto-Lei n. 208/2002 de 17 de Outubro. Diário da República - I Série A, n.ำ 240. Consultado em https://dre.pt/application/file/432497

Decreto-Lei n. 387/99 de 28 de Setembro. Diário da República - I Série A, n.ㅇ 277. Consultado em https://dre.pt/application/file/a/668070

DGFV (2004). O impacto do reconhecimento e certificação de competências adquiridas ao longo da vida: Uma mais-valia para uma vida com mais valor. Lisboa: Direção Geral de Formação Vocacional/Ministério da Educação/CIDEC.

Despacho 21974/2002 de 11 de Outubro. Diário da República - I/ Série, n.ำ 235. Consultado em https://dre.pt/application/file/2987718

Despacho Conjunto n.ำ1083/2000 de 20 de Novembro. Diário da República - // Série, n.을 268. Consultado em https://dre.pt/application/file/984786

Ecclestone, K. (2009). Lost and found in transition. Educational implications of concerns about 'identity', 'agency' and 'structure'. In J. Field, J. Gallacher, \& R. Ingram, (Eds.), Researching transitions in lifelong learning (pp. 9-27). London: Routledge.

Esteves, M. J. (1996). O retorno à escola: Uma segunda oportunidade? Trajetórias sociais e escolares dos jovens e adultos que frequentam os cursos do ensino recorrente de adultos. Inovação 9(3), 219-240.

Field, J. (2002). Lifelong learning and the new educational order. London: Trentham Books. 
Fragoso, A., Kurantowicz, E., \& Lucio-Villegas, E. (Eds.). (2011). Between global and local: Adult learning and development. Frankfurt Am Main: Peter Lan

Guimarães, P. (2008). A educação de adultos no séc. XXI: Desafios contemporâneos em prospectiva. Aprender, 9, 34-39. Consultado em http://www.direitodeaprender. com.pt/sites/default/files/uploads/aprender_9.pdf

Guimarães, P. (2011). Políticas de educação de adultos em Portugal (1999-2006): A emergência da educação para a competitividade. Braga: Universidade do Minho.

INE (1993). Censos 1991: Resultados definitivos. Portugal. Lisboa: Instituto Nacional de Estatística.

INE (2002). Censos 2001: Resultados definitivos de Portugal. Lisboa: Instituto Nacional de Estatística.

INO (2005). Iniciativa novas oportunidades. Consultado em http://212.55.143.51/documentos.aspx

Jessop, B. (1998). The rise of governance and the risks of failure: The case of economic development. International Science Journal, 155, 29-45. doi: 10.1111/1468-2451.00107

Lazarus, R. (1989). Second stage adult literacy. In C. J. Titmus (Ed.), Lifelong education for adults: An international handbook (pp. 89-93). England: Pergamon.

Lei 115/97 de 19 de Setembro. Diário da República - I Série A, n.ำ217. Consultado em https:// dre.pt/application/file/653047

Lei no 49/2005 de 30 de Agosto. Diário da República - I Série A, n.ำ166. Consultado em https:// dre.pt/application/file/245260

Leibfried, S., \& Pierson, P. (1995). European social policy: Between fragmentation and integration. Washington: The Brookings Institution.

Lima, L. C. (1998). Políticas educativas, novas (e velhas) oportunidades. In A educação na viragem do século XX: Atas das I Jornadas de Educação. Braga: Núcleo de Estudantes de Educação da Universidade do Minho.

Lima, L. C. (2005). A educação de adultos em Portugal (1974-2004): Entre as lógicas da educação popular e da gestão de recursos humanos. In R. Canário \& B. Cabrito (Org.), Educação e formação de adultos: Mutações e convergências, (pp. 31-60). Lisboa: EDUCA-Formação.

Lima, L. C. (2007). Educação ao longo da vida: Entre a mão direita e a mão esquerda de Miró. São Paulo, Brasil: Cortez Editora.

Lima, L. C. (2014). Políticas de educação permanente: Qualificacionismo adaptativo ou educação de adultos? Sensus7, 4(1), 105-121.

Liz, C., Machado, M., \& Burnay, E. (2009). Iniciativa novas oportunidades: Primeiros estudos da avaliação externa - Percepções sobre a iniciativa novas oportunidades (Caderno Temático no 2). Lisboa: Universidade Católica Portuguesa.

Loureiro, A., \& Caria, T. H. (2013). To learn and to construct knowledge in the context of work with adult education: A Portuguese case study. International Journal of Lifelong Education, 32(2), 149-164. doi: 10.1080/02601370.2012.733971

Marques, M. (1994). A decisão política em educação: O partenariado sócio-educativo como modelo decisional - O caso das escolas profissionais. Porto: Edições Afrontamento.

Marques, M. (2014). Finding and tracing the effects of governance processes in the new opportunities initiative: An outline. International Journal of Lifelong Education, 33(3), 290-308. doi: 10.1080/02601370.2014.896087

Melo, A. (2001). Uma nova vontade política de relançar a educação e formação de adultos? In A. Teodoro (Org.), Educar, promover, emancipar: Os contributos de Paulo Freire 
e Rui Grácio para uma pedagogia emancipatória (pp. 101-120). Lisboa: Edições Universitárias Lusófonas.

Melo, A., Matos, L., \& Silva, O. S. (2001). S@bert: Programa para o desenvolvimento e expansão da educação e formação de adultos, 1999-2006. Lisboa: ANEFA/GMEFA.

Melo, A., Lima, L. C., \& Almeida, M. (2002). Novas políticas de educação e formação de adultos: O contexto internacional e a situação portuguesa. Lisboa: Agência Nacional de Educação e Formação de Adultos.

Mesquita, L. (2000). Educação e desenvolvimento económico: Contribuição para o estudo da natureza presente de uma relação. Lisboa: Instituto de Inovação Educacional.

Milana, M. (2015). Debating global polity, policy crossing, and adult education. Comparative Education Review, 59(3), 498-522. doi: 10.1086/681906

Ministério da Educação (2003). Documento orientador da reforma do ensino secundário recorrente. Lisboa: Ministério da Educação. Consultado em http://www.fenprof.pt/ Download/FENPROF/SM_Doc/Mid_115/Doc_100/Anexos/rev_recorrente.pdf

OECD (2005). Education at a glance 2005: OECD indicators. Paris: OECD Publishing. doi:10.1787/ eag-2005-en

Offe, C. (1984). Problemas estruturais do estado capitalista. Rio de Janeiro: Tempo Brasileiro.

Pinto, J., Matos, L., \& Rothes, L. (1998). Ensino recorrente: Relatório de avaliação. Lisboa: Ministério da Educação.

Pires, A. L. (2007). Reconhecimento e validação das aprendizagens experienciais. Sísifo: Revista de Ciências da Educação, 2, 5-20. Consultado em http://arquivo.pt/ wayback/20070607090810/http://sisifo.fpce.ul.pt/?r=9\&p=5

Portaria n. 135-A/2013 de 28 de março. Diário da República, / Série, 1o Suplemento, n. 62. Consultado em https://dre.pt/application/file/276339

Resolução de Conselho de Ministros (RCM) n.ำ124/2005 de 4 de Agosto. Diário da República - I Série B, no. 149. Consultado em https://dre.pt/application/file/240538

Rodrigues, C., \& Nóvoa, A. (2005). Prefácio. In Rui Canário \& Belmiro Cabrito (Org.), Educação e formação de adultos: Mutações e convergências (pp. 7-14). Lisboa: EDUCA-Formação.

Rothes, L. A., Silva, O. S., Guimarães, P., Sancho, A. V., \& Rocha, M. A. T. (2006). Para uma caracterização de formas de organização e de dispositivos pedagógicos de educação e formação de adultos. In L. C. Lima (Org.), Educação não escolar de adultos: Iniciativas de educação e formação em contexto associativo, (pp. 181-204). Braga: Universidade do Minho.

Rothes, L. A. (2009). A recomposição induzida do campo da educação básica de adultos: Lógicas de apropriação local num contexto político-institucional redefinido. Lisboa: Fundação Calouste Gulbenkian/Fundação para a Ciência e a Tecnologia.

Salgado, L. (2011). (Org.). O aumento das competências educativas das famílias: Um efeito dos Centros Novas Oportunidades. Lisboa: ANQ.

Santos, B. S. (1998). Uma exigência cosmopolita: Entre o pré-contratualismo e o pós-contratualismo. In J. F. Amaral (Coord.), Europa social: Actas do Seminário Internacional (pp. 449-480). Lisboa: Fundação Calouste Gulbenkian.

Seixas, A. M. (2003). Políticas educativas e ensino superior em Portugal. Coimbra: Quarteto.

Silva, A. S. (2002). Por uma política de ideias em educação. Porto: Edições ASA. 
Trigo, M. M. (1999). Prefácio. In Melo, A., Matos, L., \& Silva, O. S. (Coord.), S@bert: Programa para o desenvolvimento e expansão da educação e formação de adultos, 1999-2006, (pp. 5-7). Lisboa: ANEFA/GMEFA. Consultado em http://opac.iefp.pt:8080/ images $/$ winlibimg.aspx?skey $=\& d o c=6784$ \&img $=221$

Trigo, M. M. (2001). O presente e o futuro da educação de adultos em Portugal. Revista Portuguesa de Pedagogia 35(1), 101-114.

Trigo, M. M. (2002). Balanço de um ano de atividade. In I. M. Silva, J. A. Leitão, \& M. M. Trigo (Orgs.), Educação e formação de adultos: Fator de desenvolvimento, inovação e competitividade (pp. 115-119). Lisboa: ANEFA. 